\title{
Knowledge transfer between building operation and building projects
}

\author{
Jensen, Per Anker; Rasmussen, Helle Lohmann; Chatzilazarou, Stamatia
}

Published in:

Journal of Facilities Management

Link to article, DOI:

10.1108/JFM-05-2018-0030

Publication date:

2019

Document Version

Peer reviewed version

Link back to DTU Orbit

Citation $(A P A)$ :

Jensen, P. A., Rasmussen, H. L., \& Chatzilazarou , S. (2019). Knowledge transfer between building operation and building projects. Journal of Facilities Management, 17(2), 208-219. https://doi.org/10.1108/JFM-05-20180030

\section{General rights}

Copyright and moral rights for the publications made accessible in the public portal are retained by the authors and/or other copyright owners and it is a condition of accessing publications that users recognise and abide by the legal requirements associated with these rights.

- Users may download and print one copy of any publication from the public portal for the purpose of private study or research.

- You may not further distribute the material or use it for any profit-making activity or commercial gain

- You may freely distribute the URL identifying the publication in the public portal

If you believe that this document breaches copyright please contact us providing details, and we will remove access to the work immediately and investigate your claim. 


\title{
Knowledge Transfer between Building Operation and Building Projects
}

\author{
Per Anker Jensen, Helle Lohmann Rasmussen and \\ Stamatia Chatzilazarou \\ DTU Management Engineering, Technical University of Denmark \\ Lyngby, Denmark
}

\begin{abstract}
Purpose - This paper aims to investigate how knowledge concerning operation and maintenance of buildings can be stored and transferred between the parties responsible for building operation and new building projects.

Design/methodology/approach - The paper is theoretically based on knowledge management with a particular focus on interdepartmental knowledge transfer between departments responsible for operation and maintenance and departments responsible for building projects in organisations with large and fast changing building portfolios. The paper includes a case study of the facilities management organisation of the Technical University of Denmark with data collection mainly by interviews with managers and staff in the relevant departments in this organisation.
\end{abstract}

Findings - The case organisation seems to be aware of the importance of sharing and transferring their organisational knowledge. Over the past five years, the organisation has developed different tools and adopted several processes, aiming at integration of the knowledge they possess from many years of operation and maintenance of the existing buildings. However, there are many situations, where the tools and processes do not work efficiently, and therefore the knowledge transfer is not sufficiently effective. It is apparent that the best results can be achieved only if the different actors involved in a construction project collaborate aiming towards the same objectives.

Originality/value - The paper presents and evaluates a case of interdepartmental knowledge transfer in an organisation, which has a strong focus on improving the interconnections between building operations and planning new building projects.

Keywords: Project management, Knowledge transfer, Building project, University campus, Building operation, Building client

Paper type: Research paper

To cite this document:

Per Anker Jensen, Helle Lohmann Rasmussen, Stamatia Chatzilazarou, (2018) "Knowledge transfer between building operation and building projects", Journal of Facilities Management, Vol. 17 No. 2, pp. 208-219. https://doi.org/10.1108/JFM-05-2018-0030 


\section{INTRODUCTION}

This paper concerns a challenging topic within the construction industry and the Knowledge Management (KM) discipline. The issue that is examined is knowledge transfer (KT) between building operation and project management of construction projects to ensure appropriate performance of new facilities.

According to literature, the involvement of Facilities Management (FM) expertise in a construction project from its early phases is of great importance (Jaunzens et al, 2001; Jensen, 2009; Hansen et al., 2010; Meng, 2013). Although it might be assumed that knowledge transfer could be approached in the same way as it is in other kind of industries, the nature of the construction industry makes it difficult. Construction firms move from one building project to another, which usually differs substantially from the previous one. The lack of distinct similarities between these building projects makes the project management team more reluctant to consider, extract and reuse knowledge that has been acquired during past projects (Lê, 2007).

The purpose of the paper is to answer the following research question: how knowledge concerning operation and maintenance $(\mathrm{O} \& \mathrm{M})$ of buildings can be stored and transferred between the parties responsible for building operation and new building projects? Besides, the paper aims to clarify the KT tools and processes that have been developed and are being used within the case organisation.

The paper is based on a case study of the FM organisation of the Technical University of Denmark (DTU) called DTU Campus Service (CAS). They are in charge of management, operation and development of all the existing facilities of the university as well as a huge construction program of new buildings at its main campus, following a number of mergers with former independent institutions. The case study examines the knowledge transfer between the building O\&M department and the department responsible for new buildings projects - the Real Estate Project Management Office (PMO). The methodology of the study is described in section 2 followed by a literature review on KM, focussing on theory on Knowledge Transfer (KT) related to the construction industry in section 3 . The case study is presented in section 4 followed by discussion in section 5 and conclusion in section 6 .

\section{METHODOLOGY}

CAS was chosen for the case study, because they currently are one of the largest building clients in Denmark, they have a large in-house departments responsible for O\&M of buildings, and earlier research (Rasmussen et al., 2014) has shown that CAS is deliberately aiming at increasing knowledge transfer between building operation and building projects. The methodological approach used during the research was divided into three stages.

In the first stage a broad literature review was conducted. The field of KM was examined, giving weight to aspects regarding KT in the construction industry and particularly in KT between FM and building design. This was supplemented by two interviews with external experts.

The second stage focused on qualitative data collection, using semi-structured interviews, which took place during spring 2015. Eight interviews were conducted with people from CAS. Further information about the interviewees are given in section 4 . The interviews were supplemented with a study of documents from CAS. 
The third stage included analysis and categorization of the data that were gathered through the interviews and document studies. The categories in which the data were placed were regarding the KT behaviour and activities that CAS uses.

\section{LITERATURE REVIEW}

KM is a relatively new management field (Alvesson and Kärreman, 2001), established on the argument that it is a challenging task, though an attractive objective, for an organisation to fully utilize the knowledge that they create or possess. The information technology revolution is one of the crucial reasons, why increased access to knowledge has become possible. KM can be described as the strategy that aims at development of organisational knowledge through accumulation of data and information, along with past experience derived from the human resources (Dubey and Kalwale, 2010).

A common way to distinguish knowledge is into two fundamentally different categories; explicit and tacit (Heisig, 2009; McBeath and Ball, 2012). The explicit knowledge of an organisation is systematic and can easily be codified and communicated. Once codified explicit knowledge can be distributed within the organisation and reused. Examples of explicit knowledge are templates, patents, reports and checklists. Tacit knowledge is non-articulated knowledge and thus inherently personal, which makes it difficult to be extracted out of human minds, formalized and disclosed in manuals in order to be shared or transferred. Tacit knowledge includes individual experience along with personal belief, perspective and values (Pan and Scarbrough, 1999; Vianello and Ahmed, 2012). This feature constitutes an obstacle to the transferability of tacit knowledge (Lundvall, 2004).

Knowledge codification is an important part of the knowledge refinement process, which includes the techniques that extract, filter, clean and reform knowledge in order to enter the various knowledge repositories. Such repositories hold both organisational knowledge and information, either in an electronic form (i.e. knowledge databases), or in a documented form (Davenport et al., 1998).

Technology has a crucial role in the acquirement and codification of organisational knowledge as it can store large amounts of knowledge, allowing its smooth distribution and re-use. Therefore, a robust Information and Communication Technology (ICT) infrastructure to support both the codification and storage of the organisational knowledge is essential. The selection of appropriate technology should be aligned with different organisational aspects. The most important aspect is organisational culture as it is the one that affects internal communication and KT, with operational, technical and cost aspects being significant as well (Smith, 2001).

Technology does not transfer knowledge on its own, but relies on the people using it. However, Alvesson and Kärremann (2001) point at IT-based tools for KM as important symbol, communicating to the people in the firm, that in this firm, knowledge is shared. Thus, ICT-based tools contribute to establish a knowledge sharing culture, and is in that regard self-perpetuating. Ahmed-Kristensen and Vianello (2015) states: “The success of the knowledge management strategy is not in the amount of information that is stored into the repositories but in how the information is reused in order to achieve a predefined aim (...)”

The success of KT is heavily based on the existence of cooperative behaviour between the participants. Appel-Meulenbroek (2014) distinguished cooperative behaviour into two main types; 
1) interaction and 2) collaboration. Interaction adds structure to how departments interrelate and describes a more formal kind of cooperation with routine activities, such as scheduled meetings and teleconferences, routine calls or standardized documentation. Collaboration represents the unstructured, affective nature of intradepartmental relationships portrayed by more informal processes and mutual understanding between the different parties, which work together sharing a common vision and the same objective. See table 1.

Table 1. Organizational cooperation, activities and communication channels (Kahn, cited in Appel-Meulenbroek, 2014)

\begin{tabular}{|l|l|l|}
\hline \multirow{3}{*}{ Interaction } & Suggested activities & Means of communication \\
\hline \multirow{2}{*}{ Collaboration } & $\begin{array}{l}\text { Deetings } \\
\text { information } \\
\text { exchange }\end{array}$ & $\begin{array}{l}\text { Meetings, committees/task forces, phone } \\
\text { conversations, phone mail, electronic mail }\end{array}$ \\
\hline $\begin{array}{l}\text { Activities to achieve goals collectively, mutual understanding, informally } \\
\text { vork together, share idea's information and/or resources, share the same } \\
\text { vision for the firm and work together as a team. }\end{array}$ \\
\hline \multicolumn{2}{|l|}{} \\
\hline
\end{tabular}

Figure 1. KT through personalization and codification strategies (Vianello, 2011)

Personalization

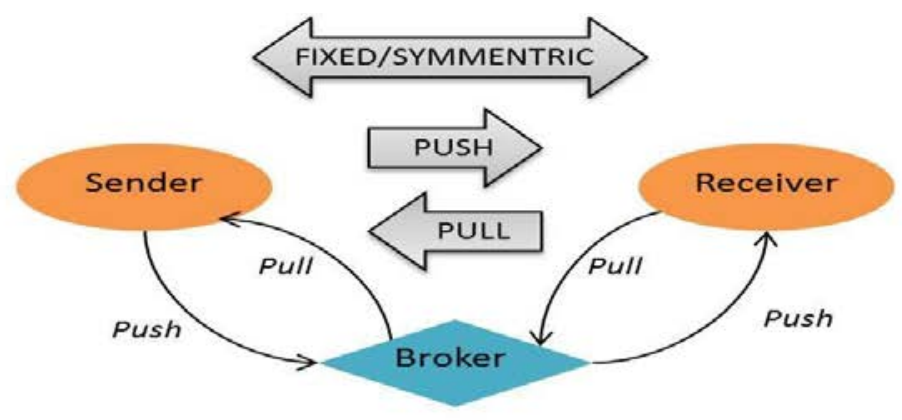

\section{Codification}

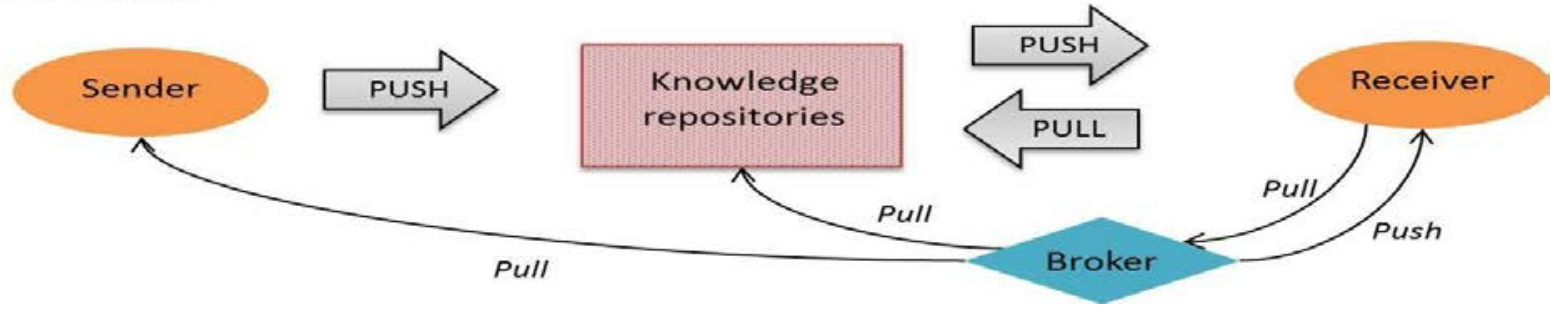


KT mechanisms are currently a hot topic in the KM field (Zuo et al., 2013). The initiation mechanisms of KT can be categorized into push, pull and fixed (or symmetric) mechanisms. Knowledge push represents an initiation mechanism, where the sender provides knowledge without any particular demand for it. Knowledge pull is a mechanism, where the receiver is the one that requests the knowledge, while a fixed KT initiation mechanism depicts the scheduled KT activities, such as regular meetings, where both sender and receiver play an active role through established interaction activities (Ahmed-Kristensen and Vianello, 2015).

Another type of categorization of the KT mechanisms is the distinction between personalization and codification strategies (Lê, 2007; Vianello and Ahmed, 2009; Vianello, 2011; Jensen, 2012; Ahmed-Kristensen and Vianello, 2015). The personalization strategies represent a more informal communication between the participants and can be related to the collaboration activities. Through these strategies, new knowledge is generated and existing tacit knowledge becomes available to the receiver. On the other hand, the codification strategies refer to the transfer of the explicit knowledge that is captured into knowledge repositories, for instance ICT-based tools as databases, related more to the interaction activities.

The distinction between between personalization and codification strategies are illustrated in Figure 1 (Vianello, 2011). It shows the three mentioned initiation mechanisms - push, pull and fixed/symmetric - are placed directly between sender and receiver in the knowledge transfer with a personalization strategy, whereas the knowledge transfer in the codification strategy is mediated via knowledge repositories and the fixed/symmetric initation mechanism is not included. In both strategies, a knowledge broker is included as an alternative or supplement to the other transfer channels. The knowledge broker can be an internal mediator or an external consultant.

\section{CASE STUDY}

The main purpose of DTU CAS is to ensure that all students and personnel are provided with the best possible physical working conditions in all DTU's 17 different locations around Denmark and Greenland. CAS is headed by a campus director with reference to the university director and is subdivided into three different departments, each headed by a director, see Figure 2.

These departments represent the core activity areas of the organisation; Real Estate PMO, Facilities Maintenance and Projects (O\&M), and Real Estate and Space Management. The organisation is physically distributed on six locations, employs approximately 180 employees and has its headquarters at the main campus in Lyngby, north of Copenhagen. The case study concerns the main campus, owned by DTU, as it is currently expanding in order to support the centralisation of the external research institutions, currently placed in rented buildings elsewhere, as well as the future demands deriving from the increase of students and staff.

The eight interviewees from CAS included the heads of the three departments as well as section leaders and project managers from the O\&M and PMO departments, whose interaction was examined. 
Figure 2. Organisation of CAS

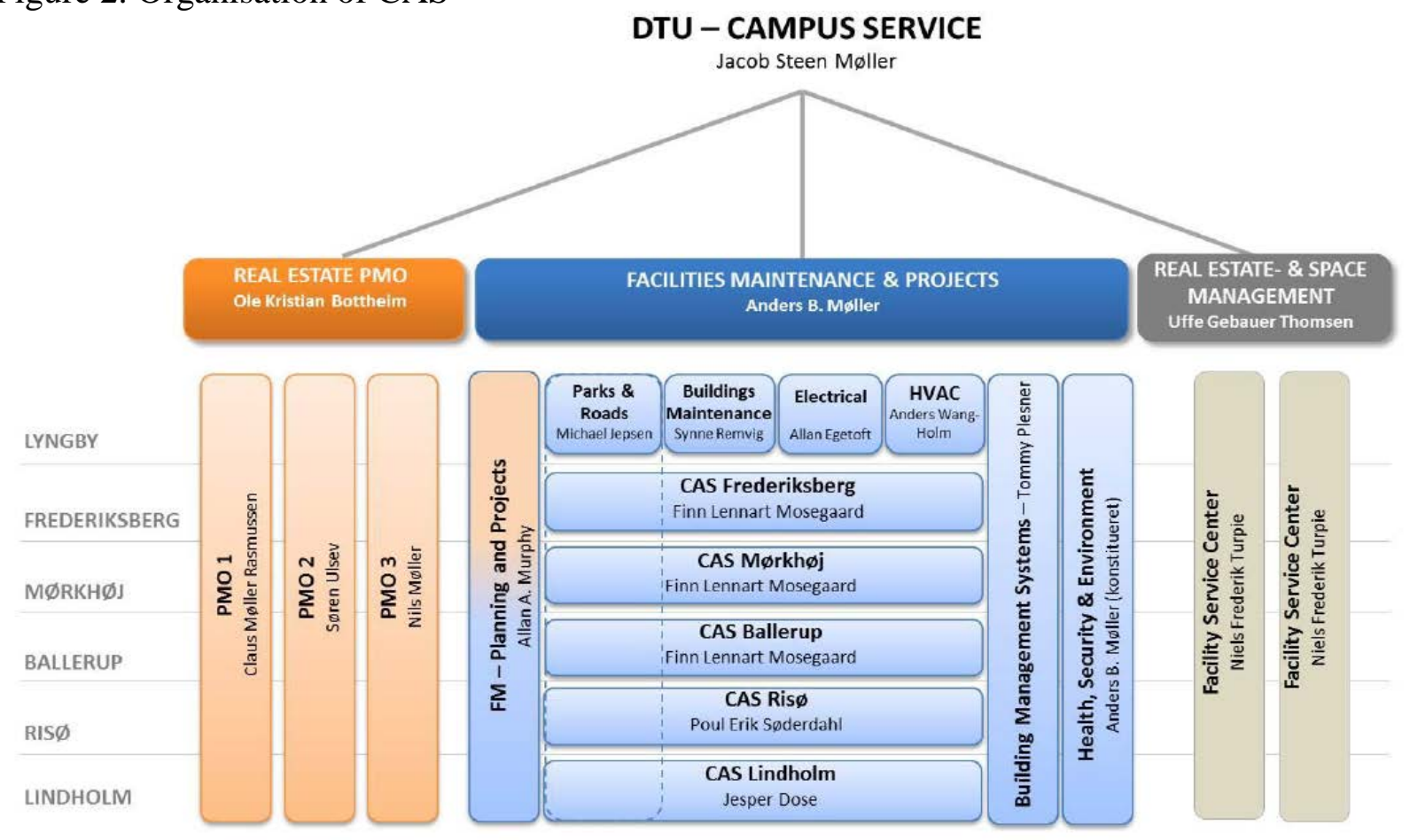

\subsection{KM in CAS generally}

According to the literature review interaction as a cooperative behaviour for KT is more structured and formal than collaboration. Interaction in CAS is established on a phase-gate model that has been developed based on the principles of PRINCE2 project management model in order to support every new construction project. A building project in CAS is divided into four main stages; Conceive, Design, Implement, and Operate (CDIO). Each of these stages is subdivided into different phases, representing the activities that take place during the project execution. All CAS departments are involved in a building project, along with external resources, depending on the phase that the project is in. Each phase is followed by a gate-point, where activities that support the interaction of the involved in the project parties occur. These activities are usually scheduled meetings or exchange of documented information for review or approval from CAS units or other project participants.

Collaboration as a type of cooperative behaviour for KT includes unstructured and informal organisational processes. Although CAS has a structured cooperative behaviour in terms of interaction, when it comes to collaboration, they have not yet achieved an adequate level within the whole organisation. A clear common goal regarding KT or KM has not been defined. Employees in CAS know that they have to share knowledge between them and transfer knowledge to another department when necessary, but a strategy has not been formally stated to clarify, why and how it should be done. The heads of CAS departments collaborate to a higher degree than their employees do, and during the interviews, a 'close relationship' is mentioned. At the time of study the three departments were placed in three different buildings at the campus, which may result in the development of subcultures within the organisation. Even though subcultures can be considered as a positive consequence, because employees feel as a part of a community and therefore may collaborate and perform better, it can prevent the development of a common 
organisational culture. However, a new building was being constructed in order to gather CAS departments, aiming also to develop a strong universal organisational culture.

According to the literature referred to in section 3, KM depends heavily on ICT-based tools. Since CAS is moving to a direction, where the knowledge arising from previous projects is intended to be shared in order to be reused, they invest in ICT systems to assure competent and efficient knowledge sharing throughout the organisation. Two such systems are the Building Information Modelling (BIM) for 3D models of both existing and new buildings and a Computer-Aided FM (CAFM) system, which will be used among other things for maintenance management. However, both systems are not fully developed and updated with data of all buildings and projects yet. CAS has furthermore implemented a project-web tool to manage documents and drawings in the building projects. CAS thereby has ICT-based tools to handle knowledge derived from the different lifecycle phases of the buildings.

\subsection{KT from O\&M to PMO}

The main activities in O\&M are the amendment of the faults that are reported through a helpdesk system, and the management of planned maintenance projects. However, its responsibilities also include transfer of knowledge created during building operation and maintenance to PMO to assist reuse of this knowledge by the project managers during their projects.

The type of KT from O\&M to PMO can be described both as knowledge push and as knowledge pull depending on the phase of the project. During the first meetings in the design brief phase of a project, according to the project model, O\&M section leaders 'push' knowledge, through the design specifications that they pass on to the project team. In this way, O\&M sets the requirements that assure the efficient future maintenance and alignment with existing buildings on campus. On the other hand, PMO project managers call meetings with O\&M section leaders and try to involve them in every project phase, in order to 'pull' knowledge useful for the project. In these meetings, the O\&M section leaders are asked to give feedback on the building projects based on for instance floor plans or 3D models.

A critical issue that has an impact on several KT activities of O\&M is, according to the interviewees, lack of human resources. The main responsibility of the O\&M section leaders is to coordinate basic operation and maintenance activities and define the new maintenance projects they are in charge of, with respect to the future needs of the buildings. Additionally, after each phase of a PMO project, they have as an extra duty to participate in meetings with the project managers and provide the project team with feedback by commenting on project drawings and documents. These tasks are time-consuming processes and sometimes O\&M section leaders cannot attend the meetings or give feedback on the projects on time. In order to improve the efficiency of the O\&M sections and support the O\&M section leaders, CAS employed extra personnel over the last years.

A rather new method that O\&M has started to use extensively in the recent past, in order to assist the KT from their department, is codification of their departmental knowledge. This codification is based on production of documents that standardize specifications or solutions and are applicable in both new construction and refurbishment projects. The main standardization method used by CAS is the development of design standards. The development of these standards started on the request of a PMO project manager, who wanted to simplify the facilitation of KT from O\&M. They define the design requirements that have been set by O\&M, having as main parameters design 
consistency, level of complexity and cost of maintenance. For instance, a toilet room standard aims to prevent designing different toilet rooms around the campus while saving time during design. The reasoning behind is that it is more efficient to maintain, for instance keep spare parts for, one type of sanitation on Campus. Design standards are generic demands and supplements the abovementioned project specific requirements in the brief for the projects. Thus, design standards are repositories for the information that heads of O\&M previously repeated orally in the brief phase of each building project.

The design standards are distributed to the project team by the O\&M section leaders in the design brief phase of each project; thus, the KT through the design standards can be described as knowledge push as shown in Figure 3.

Figure 3. KT from O\&M to PMO through design standards

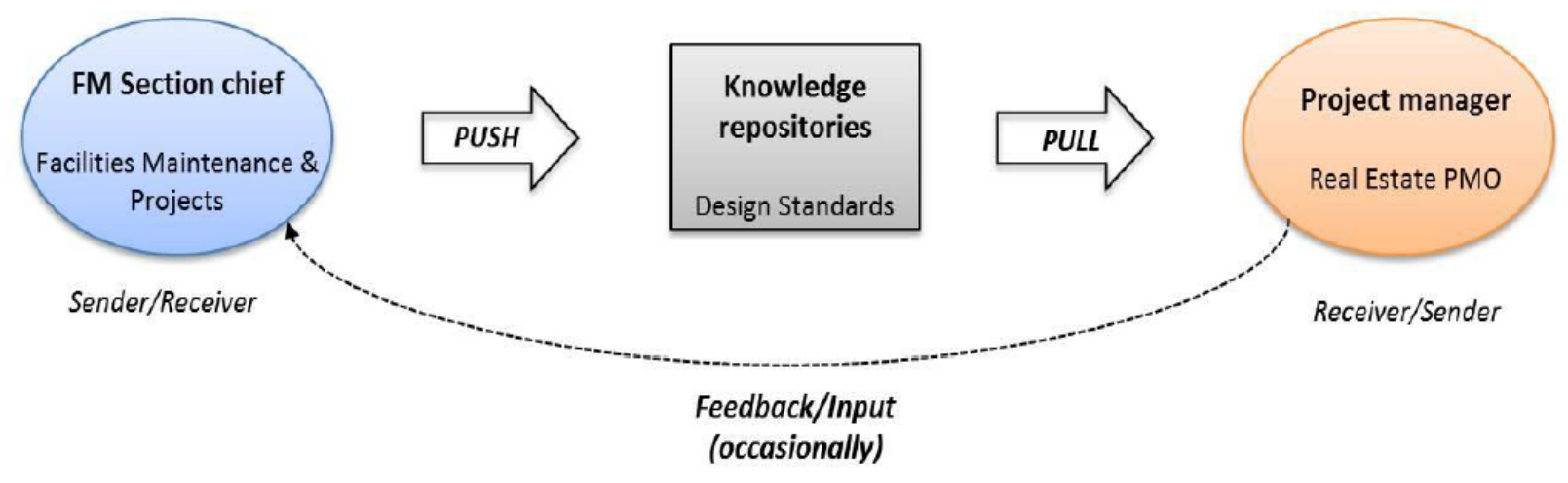

From this moment the responsibility regarding their implementation on the design of the project passes to the project managers. However, it was found in the interviews, that O\&M section leaders often discover that the decisions that have been made during the project phases are not compatible with the standards' requirements. This can happen either because the requirements set in the standards could not be applied to the specific project or because the project team disagrees with them.

\subsection{KT from PMO to O\&M}

PMO is in charge of all the new building projects of DTU. The project managers in PMO comprehend fully that after the completion of a project, O\&M personnel will inherit and be responsible for the operation and maintenance of the building; therefore the O\&M personnel needs to be familiar with the building and know how its technical systems function. The head of PMO uses what he calls the "gift metaphor", where the new building is seen as a gift that PMO is wrapping up in order to give it to O\&M. When the people in the latter department unwraps the gift, they should be able to use it; hence PMO should provide them with all the necessary knowledge and instructions. To achieve this, PMO uses processes which facilitate transfer of the knowledge that is created during the different project phases. The knowledge that arises from PMO and could be beneficial for O\&M is mainly associated with new processes, technologies or materials that can substitute the currently used. Usually, project managers try to push this knowledge to the O\&M section leaders, during their meetings after each project phase. 
However, according to the interviewed O\&M section leaders, KT from the PMO project managers is not an often occurring phenomenon. Moreover, the knowledge that is transferred is not always considered relevant or useful for the O\&M section leaders because these two participants "look at the project with different eyes". The O\&M section leaders are more concerned about buildings which maintenance does not require too much effort and expenses, while the project managers are focused on several goals for the project, for instance functionality and aesthetics. This can possibly, but not necessarily, conflict with the O\&M focus.

The amount of time that O\&M usually devotes to KT activities is limited due to their lack of human resources. Hence, KT from PMO to O\&M can be described as knowledge push, supported by the use of ICT-based systems. Project managers push the information and knowledge that arise during a project into the ICT-based systems that serve as knowledge repositories - including a projectweb called iBinder. Following, it depends on the availability of the O\&M section leaders to pull and use this knowledge, as shown in Figure 4. The same knowledge push from the project managers is happening also during their meetings with O\&M section leaders after each project phase. There, the project managers are 'pushing' information and knowledge regarding the project to the FM section leaders, requesting their comments.

Figure 4. KT from PMO to O\&M

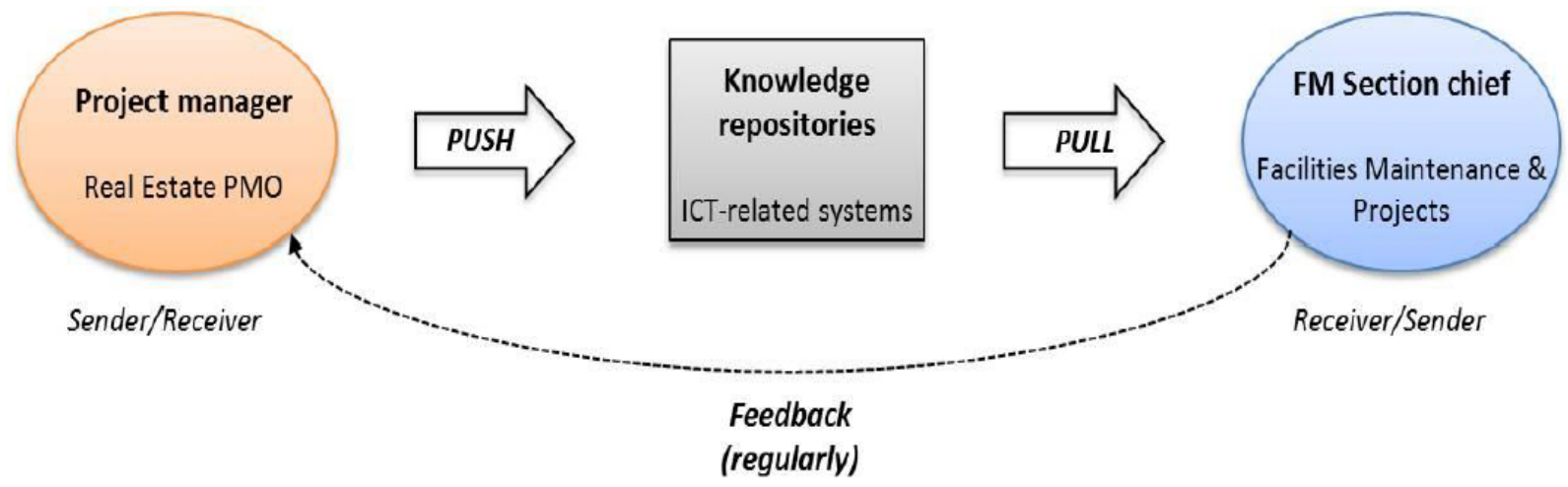

On the other hand, project managers in PMO are also engaged with tasks related to their projects, thus sometimes their work overload does not allow them to hold discussions and give feedback to the comments that they receive from both O\&M section leaders and user groups. Therefore, some of the decisions are not made in common and this can cause tensions or disappointment between the participants.

\subsection{Push and pull}

As described above, the two departments transfer knowledge between them using both push and pull. Table 2 lists the main mechanisms identified in the previous section. It is noticeable, that in contradiction to PMO, O\&M do not use pull as a mechanism to transfer knowledge. Even though knowledge transfer often take place at phasegate meetings, these are not regarded a fixed or symmetric mechanisms, because the meetings are called for by PMO concerning their project documents and information. 
Table 2. Knowledge transfer mechanisms in CAS

\begin{tabular}{|c|c|c|}
\hline Mechanism & Direction & Examples \\
\hline \multirow[t]{2}{*}{ Push } & $\mathrm{O} \& \mathrm{M} \rightleftharpoons \mathrm{PMO}$ & $\begin{array}{ll}- & \begin{array}{l}\text { Design standards } \\
\text { (generic) }\end{array}\end{array}$ \\
\hline & $\mathrm{PMO} \rightleftharpoons \mathrm{O} \& \mathrm{M}$ & 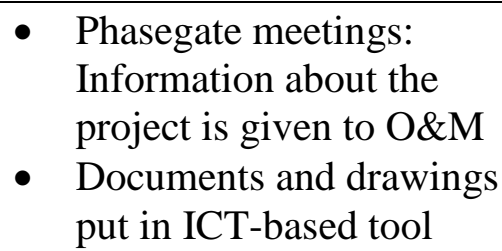 \\
\hline \multirow[t]{2}{*}{ Pull } & $\mathrm{O \& M} \longleftarrow \mathrm{PMO}$ & \\
\hline & $\mathrm{PMO} \leftrightarrows \mathrm{O \& M}$ & $\begin{array}{l}\text { Phasegate meetings: } \\
\text { Feedback from O\&M }\end{array}$ \\
\hline
\end{tabular}

\section{DISCUSSION}

The head of O\&M uses the metaphor of a "gift" to describe how PMO is completing and wrapping up a new building to finally hand it over to O\&M. One of the interesting things about a gift is the circumstance of not knowing, what is inside the wrapping. This is potentially very problematic when it concerns a new building. The finding that O\&M does not seek to pull knowledge from the projects in a formal way, suggests that O\&M would benefit from using another metaphor. O\&M occasionally finds, that decisions made later in the project phases overrule the design standards, and this further underline that it is not sufficient to push knowledge to the project in the early stages and then sit back and wait to unwrap the gift at the hand-over.

Lack of human resources was, by the interviewees in both O\&M and PMO, found to be the main reason for inconsistent use of the knowledge transfer mechanisms implemented in CAS. Lack of collaboration, supplementing interaction, such as mutual understanding, share the same vision and working as a team is possibly supplementary explanations. Figure 1 shows the possiblilty to have a broker to mediate between the sender and receiver in knowledge transfer, but it is interesting to notice that CAS according to our interviews does not use any kind of knowledge broker. CAS has started to introduce more formalised commissioning of the most technical complex building projects and a commissioning agent could act as a knowledge broker between the departments in CAS.

As described in the previous section, over the last years CAS has developed - and is still developing - various ICT-based tools. However, during the interviews the heads of the departments of CAS seemed to doubt the personnel's competences regarding using the existing ICT-based tools that assist the facilitation of KT between and within its departments. Consequently, there is a risk, that though knowledge is pushed into the repositories (see figure 3 and 4), it is seldom pulled out and consequently not applied in new building projects or to further develop FM. Four ICT-based tools were identified in CAS: Intranet, Project-web, BIM model and CAFM. As the idea is to transfer knowledge across phases of a buildings lifecycle, it is important 
that the employees knows not only how to push and pull knowledge from the tool dedicated to the life cycle phase they primarily are engaged with. However, even not fully developed, the ICT based tools play an important role regarding KT in CAS, both as far as they are increasingly developed and used, and as a symbol. The latter is important especially in CAS having no strategy concerning KM or KT.

A high level of knowledge transfer within an organization relies on both interaction and collaboration. In CAS, mechanisms have been implemented to support interactive cooperation. Meetings and development of documents have been mentioned in this paper as examples, see also table 2. Our research does not identify concrete mechanisms implemented to support collaborative cooperation. These activities intend to support mutual understanding, sharing of ideas and working together as a team with shared visions. Despite that initiatives to support the latter are not identified in our research, they are most likely to exist in CAS to a certain degree. Social events like a yearly employee trip and the annual Christmas brunch are examples. Moving the O\&M and PMO to a shared office landscape is another initiative to support collaboration. However, CAS could benefit from thinking of interaction and collaboration as equally important.

DTU's main campus has a distinctive architecture that it might be important to preserve. One of the focus areas of O\&M is the conservation of the campus architectural harmony as well as the avoidance of having buildings that are difficult or expensive to maintain. However, sometimes external architects in order to leave their footprints by designing a building that will differentiate from the existing, tend to ignore the original architecture and the general aesthetics of the buildings. Hence, it is essential for O\&M to set some requirements, by using their knowledge from operation and maintenance of existing buildings, and transfer it into the new projects. The design standards intend to serve this focus, but the design standards are not always complied with in the new building projects. Thus, it is not sufficient for O\&M to present the design standard in the beginning of the design phase. They need to follow up on their implementation during the whole design phase and go into a dialogue, if the design team has reasons not to follow the design standards.

\section{CONCLUSION}

This paper aimed to examine the knowledge transfer from building operations units to the construction project management in FM organisations to ensure appropriate performance of new facilities. According to the literature, the involvement of FM in a construction project from its early phases is crucial. In a new construction project, FM units can provide the project team in charge with valuable knowledge that supports the decision-making, ensuring that decisions with long-term benefits are made. For the facilitation of this knowledge transfer from the FM units to the project team, several tools and frameworks have been developed. ICT-based tools, such as intranet, project-webs, BIM and CAFM systems, play a key role in the facilitation of this knowledge transfer. However, these systems just serve as knowledge repositories that can store huge amount of data, information and knowledge.

The case organisation DTU Campus Service is an organisation that has been taking care of the operation and maintenance of campuses for many years; therefore, it possesses huge amounts of knowledge that can be used in the new construction projects. Over the last years, the importance of utilizing the existing FM knowledge has become apparent. For this reason, the management of the organisation has developed and established different tools and processes that facilitate the 
sharing of the existing knowledge throughout the organisation and from the FM unit to the project management of the new constructions. However, during the research it has been discovered that the case organisation has given more attention to the interaction activities, through the formation of a phase-gate project model and the development of several ICT-based systems, without focusing much on the collaboration activities within the organisation. This lack of collaboration and universal objectives within the case organisation creates several issues that lead to inefficient KT and frustration between the participants and impose the formation of a KM strategy.

Knowledge transfer within the case organisation has, according to the interviewees, improved over the last years, and the personnel are becoming aware of the importance of the knowledge transfer activities. The FM section leaders have created design standards to facilitate knowledge transfer from O\&M department to the new constructions, which ensure that the FM requirements regarding the new projects are set for the project team to consider during the design phases. On the other hand, project managers ensure that all the available data and information that derive throughout every project phase are communicated to the FM sections, through the use of an ICT-based projectweb. Both mechanisms of push and pull are implemented in CAS. However, it is found that the O\&M department do not seek to pull knowledge from PMO in a formal way. One way to improve the knowledge transfer could be to appoint a person who could act as knowledge broker between O\&M and PMO. This could be an internal mediator or an external consultant.

\section{ACKNOWLEDGMENTS}

We thank CAS for allowing us access to study the case and to our interviewees for participating in the study.

\section{REFERENCES}

Ahmed-Kristensen, S. and Vianello, G. (2015) 'A model for reusing service knowledge based on an empirical case’, Research in Engineering Design, vol. 26, January, pp. 57-76.

Alvesson M. and Kärreman D. (2001) 'Odd Couple: Making sense of the curios concept of knowledge management’, Journal of Management Studies, 38:7, pp. 995-1018.

Appel-Meulenbroek, H. A. J. A. (2014) How to measure added value of CRE and building design: Knowledge sharing in research building. PhD Dissertation, Technical University of Eindhoven.

Davenport, T. H., De Long, D. W. and Beers, M. C. (1998) 'Successful Knowledge Management Projects’, MIT Sloan Management Review, vol. 39, no. 2, pp. 43-57.

Dubey, K. and Kalwale, D. (2010) 'Knowledge Management: An Overview', Conference Proceedings, ICWET International Conference and Workshop on Emerging Trends in Technology, Mumbai, India, pp. 565-568. 97

Hansen, A. P., Damgaard, T. and Haas (de), H. (2010) 'Creating and using FM knowledge in complex building projects', International Conference Constructions Matter, Copenhagen.

Heisig, P. (2009) 'Harmonisation of knowledge Management - comparing 160KM frameworks around the globe', Journal of Knowledge Management, Vol. 13 Issue: 4, pp. 4-31.

Jaunzens, D., Warriner, D., Garner, U. and Waterman, A. (2001) Applying facilities expertise in building design. Building Research Establishment.

Jensen, P. A. (2009) 'Design integration of facilities management: A challenge of knowledge transfer', Architectural Engineering and Design Management, vol. 5 no. 3, pp. 124-135. 
Jensen, P.A. (2012) 'Knowledge Transfer from Facilities Management to Building Projects: A typology of transfer mechanisms', Architectural Engineering and Design Management, vol. 8, no. 3, pp. 170-179.

Lê,, M.A.T. (2007) Linking experience and learning: application to multi-project building environments. Engineering, Construction and Architectural Management, Vol. 14 No. 2, pp. 150163.

Lundvall, B. (2004). The economics of knowledge and learning. In: J. Christensen and B. Lundvall (ed.) Product Innovation, Interactive Learning and Economic Performance (Research on Technological Innovation, Management and Policy), 1st ed. Emerald, pp. 21-42.

McBeath A. and Ball P. (2012) 'Towards a framework for transferring technology knowledge between facilities’. Strategic Outsourcing: An International Journal, Vol. 5 Issue: 3, pp. 213-231 Meng, X. (2013) 'Involvement of Facilities Management Specialists in Building Design: United Kingdom Experience’, Journal of Performance of Constructed Facilities, vol. 27, no. 5, pp. 500507.

Pan S. L. and Scarbrough H. (1999) Knowledge Management in Practise: 'An Exploratory Case Study', Technology Analysis \& Strategic Management, 11:3, 359-374.

Rasmussen, H.L., Nielsen, S.B. and Møller, A.B. (2014) 'DTU says yes to operational friendly building at DTU - but how should it be done in practice?' EuroFM Insight, Issue 31, December 2014.

Smith, E.A. (2001) 'The role of tacit and explicit knowledge in the workplace', Journal of Knowledge Management, vol. 5, no. 4, pp. 311 - 321.

Vianello, G. and Ahmed-Kristensen, S. (2011) Transfer and Reuse of Knowledge from the

Service Phase of Complex Products. PhD-thesis. DTU Management, Technical University of Denmark.

Vianello G. and Ahmed-Kristensen, S. (2012) 'Transfer og knowledge from the service phase: a case study from the oil industry', Research in Engineering Design 23:125-139.

Zuo, M., Zhao, D. and Gao, P. (2013) 'Models for Describing Knowledge Transfer Mechanisms', Scientific Journal of Management Science and Engineering, vol. 3, no. 3, pp. 63-72. 